\title{
Lymphoblasts expressing surface IgM in the absence of kappa and lambda in Philadelphia positive acute lymphoblastic leukemia: Philadelphia chromosome positive transitional pre-B acute lymphoblastic leukemia
}

\author{
Merve Pamukcuoglu*, Kadir Acar and Gülsan Türköz Sucak \\ Gazi University Medical Faculty, Department of Hematology, Ankara, Turkey
}

\section{Dear Editor}

A 55 year old woman was admitted to the emergency room with progressive fatigue and fever. Her physical examination revealed fever $\left(38.8^{\circ} \mathrm{C}\right)$, pallor, ecchimoses in the lower extremities. Abnormal laboratory values included: hemoglobin: $7.7 \mathrm{gr} / \mathrm{dl}$, hematocrit: $23 \%$, white blood cell: 33 600/ $\mu$ l, platelets: 20 400/ $\mu$ l, lactic dehydrogenase: 2632 IU. Lymphoblasts were found in the peripheral blood smear and bone marrow aspiration revealed a hypercelluler bone marrow with diffuse blast cell infiltration. Flow cytometric analysis was positive for TdT, CD 10, CD19, CD10, D19, CD20, CD22, CD24, CD34, cyCD79a, HLADR and surface IgM (mu) with negative kappa and lambda. Cytogenetic analysis of the bone marrow performed with GTGbanding with short term unstimulated culture showed a karyotype; 46,XX,t(9,22)(q34;q11)[2]/40-44,XX[2]/46,XX [1]. Bcr-abl was positive by RT-PCR. She was diagnosed with Philadelphia chromosome positive transitional pre-B acute lymphoblastic leukemia (ALL) and HyperCVAD (hyperfractionated cyclophosphamide, vincristin, adriamycine and dexamethasone) chemotherapy and tyrosine kinase inhibitor (imatinib) was commenced. Patient succumbed to sepsis seven days after starting chemotherapy.

Transitional pre-B ALL (TPB-ALL) is a subtype of ALL where lymphoblasts are between pre-B and $B$ stage of differentiation and is reported to consists a very small subset of pre-B ALL patients. While Koehler et al. reported seventeen cases in a series of 1726 pediatric patients which consists less than $2 \%$ of the cases, López-Karpovitch et al identified 4 cases of TPB-ALL in a cohort of 60 consecutive cases of de novo adult acute ALL suggesting a higher frequency in adults $[1,2]$. Transitional pre-B ALL blasts express CD10, TdT and IgM (mu) heavy chain without kappa and lambda light chains and lacks FAB L3 morphology and the $(8 ; 14),(8 ; 22)$, and $(2 ; 8)$ translocations [1-3].
Koehler et al. also showed some chromosomes abnormalities in 7 of 17 patients [1]. However no particular cytogenetic abnormality has been found to be associated with transitional ALL. On the other hand Callera et al. reported a case with ringed chromosome 16 [3]. The presented patient, to best of our knowledge is the first case of TPBALL with philadelphia chromosome. Philadelphia chromosome is the most frequent cytogenetic abnormality in adult ALL, seen in $25-30 \%$ of the cases and even more common above the age of 50 [4]. The present data is immature to comment on the prognosis of TPB-ALL although an excellent prognosis is reported in pediatric cases. Philadelphia chromosome remains to have a dismal prognosis even in the era of tyrosine kinase inhibitors [5] and we believe such a cytogenetic abnormality would dominate the clinical outcome rather than the developmental stage of the lymphoblasts. The clinical significance of specific cytogenetic abnormalities in TPB ALL should be validated with further studies.

\section{References}

1. Koehler M, Behm FG, Shuster J, Crist W, Borowitz M, et al. (1993) Transitional pre-B- cell acute lymphoblastic leukemia of childhood is associated with favorable prognostic clinical features and an excellent outcome: a Pediatric Oncology Group study. Leukemia 7: 2064-8. [Crossref]

2. Lopez-Karpovitch X, Piedras J (1999) Transitional pre-B cell acute lymphoblastic leukemia in adults. Am J Hematol 61: 274-6. [Crossref]

3. Callera F, Lopes CO, Rosa ES, Mulin CC (2008) Adult transitional pre-B acute lymphoblastic leukemia associated with ring chromosome 16. Cancer Genet Cytogenet 183: 131-2. [Crossref]

4. Appelbaum FR (2005) Impact of age on the biology of acute leukemia. American Society of Clinical Oncology 2005 education book. ASCO; 528-532.

5. Lee HJ, Thompson JE, Wang ES, Wetzler M (2011) Philadelphia chromosome-positive acute lymphoblastic leukemia: current treatment and future perspectives. Cancer 117: 1583-94. [Crossref]
Copyright: (C2018 Pamukcuoglu M. This is an open-access article distributed under the terms of the Creative Commons Attribution License, which permits unrestricted use, distribution, and reproduction in any medium, provided the original author and source are credited.
Correspondence to: Merve Pamukcuoglu, Gazi University, Medical Faculty 06500 Beşevler/ Ankara Türkiye, Tel: +90 312 2025511; Fax: +90 312 2236714; E-mail:drmpamuk@yahoo.com

Key words: transitional pre-B ALL, Philadelphia chromosome, cytogenetic abnormalities

Received: December 28, 2017; Accepted: January 17, 2018; Published: January 20,2018 